\title{
APICULTURA NA COMUNIDADE AREIAS EM SISTEMAS AGROECOLÓGICOS E DE PRODUÇÃO ORGÃNICA ${ }^{1}$
}

Organic beekeeping in agroecological systems at the "Areias" community ${ }^{1}$

\author{
Elaine Barbosa Muniz ${ }^{2}$ \\ Euclides Reuter de Oliveira ${ }^{3}$ \\ Alzira Salete Menegat ${ }^{3}$ \\ Andrea Maria de Araújo Gabriel ${ }^{3}$ \\ Osvaldo Souza Carbonari ${ }^{4}$ \\ Érika Rosendo de Sena Gandra ${ }^{5}$ \\ Jefferson Rodrigues Gandra ${ }^{3}$ \\ Thaís Lemos Pereira ${ }^{6}$ \\ Fabio Pereira Nunes ${ }^{7}$ \\ Gessica Cristina Garcia Rodrigues ${ }^{8}$ \\ Adrielly Aparecida do Carmo ${ }^{8}$ \\ Willian da Silva Gouvea
}

Resumo: Objetivou-se com este trabalho, compartilhar os resultados obtidos com o projeto de extensão: "Sistema orgânico e agroecológico de criação de abelhas na comunidade Areias"PROEX/UFGD, assentamentolocalizado no Município de Nioaque,MS.O enfoque da ação esteve direcionado nas técnicas de manejo com abelhas, para a produção do mel, que fossem apropriadas para o êxito da atividade naquela região, lugar de área pantaneira. Com essa atividade, pretendeu-se à autosuficiência dos assentados, para futuramente, por meio da produção de mel, alcançar em melhoria alimentar e também geração de receita e renda. Durante a ação foram desenvolvidos, mensalmente, cursos práticos e teóricos, associados ao acompanhamento das atividades diversas, tendo, nesse processo, o cuidado de atentar para cada época do calendário de manejo apícola. $\mathrm{O}$ acompanhamento eo alcance dos objetivos programados foram avaliados a cada 30 dias. Após encerramento de cada etapa na escala de produção, os envolvidos foram reunidos para avaliar as atividades realizadas, mediante painel geral, para que assim os dados quantitativos e qualitativos, fossem colhidos de forma participativa. Desta maneira os produtores puderam fazer uma profunda

\footnotetext{
${ }^{1}$ Trabalho apoiado pela PROEX/UFGD e CNPq

${ }^{2}$ Docente da UNIOSTE, Marechal Cândido Rondon, PR, (ebmuniz@yahoo.com.br)

${ }^{3}$ Docentes da UFGD, Faculdade de Ciências Agrarias, Dourados, MS, (euclidesoliveira@ufgd.edu.br)

${ }^{4}$ Agrônomo autônomo (Apiario Carbonari)

${ }^{5}$ Bolsista de Pós-doutorado (PNPD - Capes)/UFGD (erica.sena@gmail.com)

${ }^{6}$ Mestranda do Curso de Zootecnia/UFGD (thais-lemos01@ @otmail.com)

${ }^{7}$ Discente do Curso de Residência Agrária: Agroecologia, Produção e Extensão Rural/UFGD

(fabiojoaoedite@ hotmail.com)

${ }^{8}$ Discente do curso de Zootecnia/UFGD
} 
reflexão dos encaminhamentos realizados durante todo o processo, identificando as possibilidades de êxito, bem como os problemas que ocorreram, favorecendo a construção de sistemas melhorados.Houve comprometimento de todos os envolvidos na execução desta prática, que após a primeira coleta de mel verificou-se um resultado satisfatório em relação ao aspecto econômico, bem como propiciou satisfação nas relações sociais comunitárias, pois as diversas reuniões e atividades desenvolvidas coletivamente uniram as famílias da comunidade. Isso promoveu o despertar de interesse em outras famílias do assentamento Areias, que passaram a manifestar o desejo em integrarem o grupo e atuarem com a apicultura.

Palavras-chave: Abelha, assentados, extensão universitária, sustentabilidade ambiental.

Abstract: The aim of this work was to share the obtained results from the extension project entitled "Organic beekeeping in agroecological systems at the Areias community" -funded by PROEX/UFGD, developed with peasant family farms, settlements of agrarian reform, at the city of Nioaque - MatoGrosso do Sul state. The activities were mainly directed to the management techniques of bees for honey production, in a wetland area. During the monthly orientations, courses covering theoretical overview and practical training on beekeeping were given to the peasants, associated with the monitoring of the activities, giving careful attention to each stage of the year based on the beekeeping calendar. The monitoring and the achievement of the objectives set were evaluated every 30 days. After enclosing each stage of the production scale, the peasants involved in the activity were gathered together and the activities evaluated through the general panel, so that the quantitative and qualitative data were collected in a participatory manner. This way the producers could make a reflection of the activities done during the whole process identifying the possibilities of success, as well as the problems that happened, consequently favoring the construction of improved systems. Because all the participants were very committed and involved in the execution of this practice, the first honey collection was economically satisfactory and it provided satisfaction in the community social relations, as several meetings and activities developed collectively, united the families to the community. As a consequence, other families from the Areias community becameinterested and expressed their desire to join the group and work with beekeeping.

Key words: bee, peasant farmers, university extension, environmental sustainability 


\section{Introdução}

Os valores pagos pelos alimentos convencionais, comparado aos orgânicos, não estão computados diretamente nos preços estabelecidos. Deve se levar em consideração que os custos de maneira indireta também são referentes à contaminação ambiental e alimentar, a perda produtiva dos solos, uso inadequado da água, assoreamentos de rios, danos causados a biodiversidade e outros desequilíbrios que podem ser reduzidos quando se trabalho com o sistema orgânico(REIS,2003).

Nesse contexto da pequena produção, nos dias atuais, a agricultura orgânica é uma prática que vem conquistando espaço, especialmente pelo fato de que com essa atividade não se utiliza agrotóxico e nem fertilizantes químicos, promovendo alimentos mais saudáveis. Dessa forma, atualmente se percebe uma mudança no comportamento alimentar do consumidor, observando mudanças de hábitos, com preocupação no que se refere, principalmente, a qualidade sanitária e nutricional. Estas mudanças estão ligadas a valorização de atributos que caracterizam certo produto, determinando a decisão final do consumidor (LAGO et al.,2006).

Esta prática vem conquistando espaço e caminha de encontro aos desejos dos consumidores pelo fato de que na produção orgânica, se obtém alimentos saudáveis, além de não causar prejuízos nas pessoas envolvidas com o processo, durante as etapas de produção. Além disso, a agricultura orgânica traz como vantagens o equilíbrio microbiológico do solo, sem degradar a biodiversidade, o que auxilia na preservação de pássaros, insetos e outras espécies do local.

Vale destacar que nos valores pagos pelos alimentos convencionais, por vezes menores, se comparados aos orgânicos, neles não está agregado todos os elementos que devem ser computados diretamente nos preços estabelecidos, visto que no preço final de cada produto, se deve levar em consideração também os custos produzidos de maneira indireta. Aponta-se, na produção convencional, aqueles referentes à contaminação ambiental e alimentar, assim como a perda produtiva dos solos, do uso inadequado da água, do assoreamento de rios, enfim, dos danos causados a biodiversidade e outros desequilíbrios que não aparecem no valor total do produto. Na produção orgânica esses elementos prejudiciais podem ser reduzidos (REIS,2003).

No conjunto da produção orgânica, no estado de Mato Grosso do Sul, a qual se encontra em sua fase inicial, destaca-se a atividade da apicultura. Esta atividade tem se 
mostrado interessante na geração de renda para os pequenos produtores, especialmente aqueles de assentamentos rurais, sendo uma atividade que se enquadra no uso sustentável dos recursos naturais, uma vez que em seu processo de desenvolvimento não ocorre a remoção da cobertura vegetativa nativa, ou seja, sem degradação do meio ambiente (BOTHet al, 2009). Com ela evita-se maiores desgastes nos solos dos assentamentos, lugares que em sua maioria, na fase anterior a sua formação, passaram por intenso manejo, nem sempre adequado, como aquele da produção de cana de açúcar e da formação de pastagens, muitas vezes apenas exigindo do solo, sem efetuar recuperação adequada, levando ao esgotamento das áreas, que com a desapropriação, receberam famílias sem terras, em sua maioria descapitalizadas e que nelas imprimiram a pequena produção.

No entanto, para que obtenham sucesso na produção, é necessária adoção de estratégias corretas para que os integrantes da agricultura familiar consigam desenvolver as atividades alcançando êxito produtivo e também meios adequados para chegarem até o consumidor, principalmente mediante utilização de estratégias de marketing. Assim, a compreensão dos mecanismos de geração de renda, dentro da unidade familiar, tornam-se tão relevantes quanto a preocupação com os cuidados na melhoria do solo, visto que na medida em que permitem identificar os fatores estratégicos, isso poderá propiciar o conhecimento de razões estruturais, instrumentais, econômicas, sociais e culturais especialmente da comunidade consumidora, levando a uma produção consciente em diversos graus: nos cuidados ambientais, nos interesses dos produtores e nas necessidades dos consumidores. Esses aspectos aparecem na apicultura em áreas de assentamentos de Mato Grosso do Sul, especialmente no assentamento Areias.

Assim, objetivou-se com este trabalho compartilhar saberes acadêmicos e experiências locais, compartilhados com 26 agricultores familiares, assentados na comunidade Areias, no município de Nioaque, caracterizados todos como pequenos produtores rurais, desenvolvendo diversas atividades no assentamento, dentre elas a apicultura, que lá se configura como nova atividade. A intenção foi de reunir os saberes científicos, nutridos por professores e alunos da Universidade Federal da Grande Dourados/UFGD, associando-os com as experiências acumuladas pelos assentados em seu fazer no processo produtivo com a agricultura familiar, fomentando a apicultura no local. 


\section{Material e Métodos}

O assentamento Areias foi instalado no ano de 2008, em uma área desapropriada para fins de reforma agrária, procedimento efetivado pelo Governo Federal, por meio do Instituto de Colonização e Reforma Agrária/INCRA (NUNES et al., 2013), sendo sua área inicialmente cortada em 63 lotes de reforma agrária, com média de 10 hectares cada. Posteriormente a área do assentamento foi ampliada, agregando novos lotes, que atualmente somam um total de 81 lotes, com média de 10 ha. No local há, ainda, duas áreas de reservas de uso coletivo, com abrangência de 1.630 ha de área total, as quais apresentam córregos nas extremidades de cada reserva legal, com matas ciliares, cobertas por vegetação de mata e/ou recomposição do cerrado. Ambas as reservas são locais que apresentam elevado potencial para a implementação da atividade de apicultura, visto que nelas se encontra uma flora com diversidades propicias para o trabalho das abelhas, na produção de mel.

Para a organização do grupo da apicultura, considerando o total de famílias assentadas, se envolveramno projeto de extensão, que culminou com os resultados que ora são apresentados, um total de 26 assentados, os quais manifestaram interesse pela organização do apiário para fins de produção de mel.

É preciso destacar que essa ação decorre de desdobramento de um projeto anteriormente desenvolvido naquela comunidade, no ano de 2013 a 2015,durante as atividades do curso de Pós-Graduação (nível de especialização), intitulado Residência Agrária: Agroecologia Produção e Extensão Rural,oferecido pela UFGD,em parceria com o MDA/INCRA/PRONERA, para pessoas deassentamentos rurais e técnicos de ATERs de Mato Grosso doSule também de ações doNúcleo de Agroecologia e Produção Orgânica Animal e Vegetal, implantado na UFGD, numa parceria com o CNPq.Dentre os/as alunos/as que faziam parte do referido curso de especialização, um deles é proveniente daquela comunidade, e durante o curso manifestou o desejo de ampliar conhecimentos em relação a apicultura. Aproveitando essa manifestação, naquele momento,docentes da UFGD iniciaram os trabalhos de extensão universitária no Areias, com um grupo deoito famílias, que totalizavam 10 pessoas, compredisposição para apicultura. De início foraminstaladas 15 caixas de abelhas e para as tarefas iniciais do grupo, as coordenações do curso e do núcleo disponibilizaram um quite de marcenaria completo, para que assim os próprios 
assentados produzissem osequipamentos que necessitavam, dentre eles caixas emelgueiras. Foi disponibilizado também tijolos para construção de umgalpão que serve como estrutura de trabalho,e também a aquisição de dez enxames de abelhas contendo rainhas selecionadas.

Com o término do curso e diante do entusiasmo dos assentados em relação a apicultura, professores da UFGD, encaminharam novos projetos para a comunidade do Areias, dando continuidade a extensão universitária, visando assim consolidar o grupo da apicultura. E assim foi iniciado outro projeto, que resulta nesse artigo, o qual foi desenvolvido no período de 01 de janeiro de 2016 até 31 de dezembro de 2016, com auxílio da PROEX/UFGD, numa nova etapa, esta que envolveu 26 assentados rurais.

A nova etapa iniciou-se com reuniões junto ao grupo de famílias com a finalidade de interagir e explicar o envolvimento da UFGD na proposta de trabalho. Naquele momento foram realizadas explicações que pudessem trazer a compreensão sobre a importância do desenvolvimento desta prática para todo o conjunto de famílias assentadas, bem como dos professores/as e alunos/as universitários/as, estimulando a atividade apícola como mais uma forma de produção para as famílias rurais, visando fonte alimentar e geração de renda alternativa, além de incentivar a prática de produção em grupo, desenvolvida de forma comunitária, fortalecendo a dimensão do coletivo entre as famílias.

Assim, no desenvolvimento das ações do projeto, nesse segundo retorno a comunidade Areias, foram realizadas reuniões participativas para planejamento de implantação e desenvolvimento das atividades. Os assentados foram acompanhados e orientados pelo coordenador da ação de extensão e assessorados por um profissional da área,representando a Empresa Apiário Carbonari, em relação a todas as etapas que envolveu a atividade apícola. Para isso, ocorreram visitas a cada 30 dias, com explanações teóricas e práticas que tiveram duração de oito horas diárias. A cada etapa de apresentação do curso foram oferecidas informações, coletado experiências dos assentados e também estabelecidas tarefas práticas que eram debatidas durante as visitas subsequentes.

Cabe salientar que esses encontros se estendiam ao longo de todo o dia, e neles diversos aspectos compuseram cada momento: o primeiro momento era iniciado 
com um excelente café da manhã ${ }^{9}$, onde o aroma do café da roça, acompanhado do cheiro do bolo e doces caseiros, criava um ambiente favorável para a ação programada para ser desenvolvida naquele dia. Isso vinha acompanhado de conversas corriqueiras que giravam em torno do clima, da produção, do que estavam planejando oferecer para o almoço naquele dia, enfim, diálogos que demonstravam a empatia que havia se estabelecido entre os de fora (universidade) e os de dentro (assentados), denotando que ambos se sentiam "em casa", fatores necessários na extensão universitária, visto que é fundamental que as pessoas envolvidas com a ação (seja docentes, discentes e membros da comunidade) se reconheçam, se enxerguem nela, para que assim ocorra diálogos frutíferos e se obtenha, ao final da ação, amplo resultado, extrapolando a dimensão produtiva, como recomenda os referenciais da extensão universitária.

Já no segundo momentodo dia, após o café da chegada e a descontração que o mesmo promovia,eram iniciadas as tarefas propriamente ditas, que se constituíam de discussões teóricas, realizadas no quintal das

\footnotetext{
${ }^{9}$ Mesmo que a chegada ao local acontecesse por volta das 8 horas, devido a distância de quase 300 quilômetros que separa o município de Dourados sede da equipe da UFGD-, do assentamento Areias, em Nioaque, o primeiro momento era do café e da conversa solta.
}

casas dos assentados, aproveitando a sombra das mangueiras, criando um ambiente propício paradebater conhecimentos, ouvir as dúvidas, bem como as conclusões práticas que os mesmos haviam chegado com o fazer prático no apiário.

$\mathrm{Na}$ sequência dos trabalhos quando da visitação, o terceiro momento consistia com aquele do almoço, outro momento de descontração do grupo, aproveitando para saborear o delicioso alimento preparado no fogão caipira, etapa que normalmente ficava sob a responsabilidade das mulheres do grupo, sendo servida para todos. Nesse momento prevalência o silencio, onde era possível ouvir a degustação do alimento, acompanhada de breves comentários sobre seu saber.

Na sequência do dia, após o almoço, ocorria a visita ao apiário, assim como visitação na fábrica de caixarias objetivando em todos esses lugares compreender a etapa em que os assentados estavam com a produção, bem como compartilhar orientações técnicas na fabricação dos materiais, e também orientações com o manejo das abelhas. Estesespaços/momentosse consistiam na oportunidade dos integrantes do grupo apontarem dúvidas e mudanças que haviam promovido com o desenvolver da atividade, visando obterem melhores resultados. 
Essa interação entre docentes, discentes da UFGD com pessoas da comunidade nos encaminhamentos das atividades junto ao apiário aponta para um procedimento teórico-metodológico em construção, o qual decorre das experiências com a extensão universitária como debatido por Esmeraldo et al, quando destacam que é fundamental para a academia,

... dialogar com os saberes locais para, em conjunto, produzir princípios, conceitos e práticas que avancem na recuperação dos saberes, que são resultado do trabalho humano, cotidiano, elaborado na relação integrada com a natureza, que produz habilidades, e saberes cognitivos que são transmitidos geracionalmente (ESMERALDOet al., 2014, p.125).

$\mathrm{E}$ as autoras continuam apontando a importância da reciprocidade entre todos os envolvidos com projetos de extensão que tenham a finalidade de fomentar o saber local e coletivo e assim promover,

... uma construção coletiva do conhecimento, aplicando métodos participativos que possam fortalecer $\mathrm{e}$ empoderar os saberes populares produzidos historicamente, na experiência prática, assumindo assim, postura política e ética ao refutar a imposição dogmática da ciência clássica.

A construção coletiva do conhecimento, promovida pelo diálogo entre os saberes populares e acadêmicos, procura superar a perspectiva difusionista da transferência de tecnologias, garantindo uma maior e melhor compreensão das realidades locais. Esse processo de construção,

fundamentado na interdisciplinaridade e no diálogo de saberes, permite o rompimento com a educação compartimentada [...] Essa postura exige uma reorientação dos enfoques teóricometodológicos que fundamentam e ainda orientam a elaboração das atuais linhas de pesquisa e das grades curriculares dos cursos de Ciências Agrárias, essencialmente baseadas na lógica da maximização 
produtividade bruta pela utilização dos pacotes agroquímicos (ESMERALDOet al., 2014, 128)

Os aspectos apontados pelas autoras, de atentar para que os saberes locais compusessem os trabalhos com as abelhas no assentamento Areias,se fizeram presentes nas discussões dos diversos encontros naquela comunidade, onde o grupo envolvido ateve-se a preocupação de inserir inovação tecnológica, mas considerando o universo das experiências acumuladas, como indicado por Sá e Molina (2014).

Assegurada a troca de conhecimentos, evitando unicamente a transferência, os trabalhos seguiram pautadosem todas as etapas da instalação de apiário visando produção de mel, mas considerando especialmente, o ambiente natural ocupado com a atividade. Nesse sentido, constatou-se a importância das abelhas no processo da polinização e consequente produção de frutos e sementes viáveis na natureza que circunda o apiário.

Além disso, foram realizadas montagens do calendário apícola tendo como referenciais as características climáticas e ambientais da região. Ateve-se, ainda, a preocupação com a autonomia do grupo, e por isso a orientação teórica e prática de como proceder na captura de enxames, visando eliminar assim, os custos empregados para a aquisição dos mesmos no mercado, agregando maior valor a atividade.

Outro aspecto a destacar nos trabalhos em grupo, se refere a desenvolver predisposição para motivação entre todos os participantes, proporcionado aos docentes e discentes da UFGD e pequenos produtores rurais, ampliação de aprendizados para o desenvolvimento de suas atividades na área rural, assim como integração das pessoas envolvidas, desde a universidade ao meio rural.

Para sanar parte das dificuldades dos assentados em termos de produção e geração de renda local, o grupo de produtores do Assentamento Areias, além de trabalharem juntos em mutirão, também se articulam politicamente para trazerem benefícios para o assentamento como um todo.

Após o encerramento de cada etapa, os produtores envolvidos se reuniram para avaliarem as atividades. Isso ocorreu mediante painel, para que os dados quantitativos e qualitativos fossem colhidos de forma participativa.

\section{Resultados e Discussões}

2017 | Volume 4 | No 07 ISSN: 2358-3401 
Observou-se que as orientações e os acompanhamentos oferecidos aos assentados quanto à criação mais adequada de abelhas apresentaram resultados positivos. Os assentados optaram por um trabalho em conjunto o que promoveu melhor desempenho na atividade, porque reuniu em um só grupo de trabalho as diversas experiências que cada um trazia, vivenciadas ao longo dos tempos e que associadas as técnicas repassadas por professores da UFGD e assessores especializados com a apicultura, contribuiu para ampliar os conhecimentos do grupo em relação a produção de mel.

Cabe salientar que à medida que novos assentados forem aderindo a apicultura, esta atividade poderá ampliar mais e se fortalecer,o que possibilitará meios para aumento da produção de mel, culminado com aumento do retorno financeiro para o grupo.

Cumpridas as diversas etapas do projeto, com oficinas com temas diversos quanto a atividade apícola, observou-se que houve a conscientização dos participantes sobre a importância das abelhas no processo da polinização e consequente produção de frutos e sementes viáveis. Os assentados puderam entender que as abelhas, além de produzirem o mel, um produto que melhora a alimentação local e também promove melhoria na renda familiar, com a venda do excedente, traz a possibilidade de melhoria com a produção de outros produtos produzidos na comunidade. Isso porque as abelhas, no momento em que coletam o néctar de diversas espécies, promovem nelas a reprodução cruzada, e isso resulta na produção de frutos de melhor qualidade e com mais sementes, podendo inclusive colaborar em programas de restauração ambiental e recuperação da flora original.

Nesse sentido o estudo de Souza et al. (2003) apresentou dados quanto a melhoria no cafezal que ao estudarem a cultura de café (Coffea arabica L., var. Mundo Novo), quanto à biologia floral, a frequência, comportamento dos insetos na flor e verificar a produção de frutos,concluíram que a polinização realizada pelas abelhas Apis mellifera provocou aumento quantitativo (38,79\%, em 1993 e 168,38\%, em 1994) na produção de grãos de café.

Outra ação desenvolvida foi a montagem do calendário apícola na região para um melhor planejamento das atividades com a ajuda da assessoria técnica. Dada a importância de identificar a flora apícola, caracterizá-la quanto ao hábito das plantas, observar a época de floração e analisar se existe relação entre a época de floração e fatores climáticos, Lopes et al. (2016) concluíram que o conhecimento da flora 
apícola de uma região é fundamental para a criação racional das abelhas. Desta forma,ocorreu uma organização dos trabalhos pelo grupo possibilitando alcançar as tarefas em cada etapa durante todo o ano, desde a fabricação das caixas e melgueiras, limpeza dos apiários, captura de enxames e retirada do mel.

Os assentados se apropriaram, na teoria e na prática, de como proceder na captura de enxames e isso, segundo Soares et al.(1998),pode acorrer com o auxílio de caixas iscas que são colocadas na natureza. Existem duas épocas na natureza em que acontecesse a movimentação das abelhas, uma delas é a enxameação que tem seu início em agosto e termino em outubro, com uma ocorrência de $62 \%$; a outra ocorre quando do abandono das abelhas de sua moradia, em busca de outro local para se instalarem, fato que ocorre entre os meses de março, abril e maio, correspondendo a $28 \%$ das movimentações das abelhas.

Vencida a etapa das discussões técnicas junto ao grupo, a partir do momento que todos os trabalhos/etapas programadas com a ação foram desenvolvidos (as), ocorreu maior motivação entre os participantes. Os integrantes do grupo puderam comprovar que a apicultura é uma atividade que gera uma renda considerável ao produtor e que demanda baixos investimentos, tanto para iniciar a atividade como para sua manutenção, fator que gerou contentamento e envolvimento entre os integrantes do grupo. Outro ponto interessante desta prática consiste em sua relação com o ambiente, relacionado com a polinização, tanto de espécies nativas como de cultivadas, realizada pelas abelhas.

Dessa forma, cabe salientar que este trabalho proporcionou aos docentes e discentes da UFGD, assim como para os pequenos produtores rurais, um aprendizado para o desenvolvimento de suas atividades na área rural, com envolvimento de todos, numa relação entre a teoria e a prática, implicando em experimentação de campo.

Como resultado da extensão universitária pode-se afirmar que a busca de informação ocorre no contexto de uma ação, de uma tarefa, de uma necessidade imediata ou programada, envolvendo coleta e análise de dados levantados, bem como a definição de seu uso. A busca e a disponibilização de informação colaborativa se concentram em grupos de pessoas que a realizam com base na ideia de que a informação nem sempre é uma atividade possível de se realizar solitariamente, por isso as pessoas buscam colaborar de maneira distinta. Dessa forma, a colaboração institucional tem sido um componente útil e por muitas vezes 
necessários para atender projetos complexos que envolvem configurações diversas, atores e ambientes diversos (SANTOS, 2015).

Outro resultado que é preciso enfatizar com a ação no Assentamento Areias é o da integração entre as áreas de conhecimentos (relação de discentes e docentes de vários cursos) com o propósito de um funcionamento harmonioso pela soma dos esforços e que impulsiona o crescimento da atividade, ou seja, todos ganham quando estão unidos porque criam meios para intercambio de conhecimentos, experiências, dúvidas e possibilidades. Integrar tempo, custos, recursos e outras áreas de conhecimento dentro de um projeto não é uma missão simples, visto que é uma tarefa que, embora deva ser liderada pelo coordenador dos projetos, depende também do apoio de todo os seus participantes.

Pode-se afirmar, ainda, que houve capacitação técnico científico por meio de orientação específicas ao manejo apícola onde o trabalho enfocou basicamente debates, treinamentos e oficinas de capacitações do grupo envolvido, com apresentação de toda a teoria, demonstração da prática da atividade, orientação de leituras específicas. A capacitação técnica científica é uma ferramenta de valorização e aumento de competição de mercado, pois com o conhecimento os assentados trabalham de forma adequada e produtiva com resultados positivos(CARVALHO et al.,2015).

A divulgação tecnológica dos resultados da ação ${ }^{10}$ ocorreu por meio de publicação, onde os produtores puderam fazer uma reflexão dos seus problemas e identificando a construção de sistemas melhorados ${ }^{11}$.

\footnotetext{
${ }^{10}$ Cabe salientar que alguns resultados (da primeira fase do projeto) podem ser encontrados em um vídeo da apicultura no assentamento Areias estão disponíveis no endereço:

http://int.search.tb.ask.com/search/video.jhtml?n=783a $37 \mathrm{e} 8 \& \mathrm{p} 2=\% 5 \mathrm{ECPC} \% 5 \mathrm{Echr} 999 \% 5 \mathrm{ES} 20164 \% 5 \mathrm{E} \& \mathrm{pg}=$ video \&pn=1\&ptb=86555FA2-93A0-425D-971A54D2EF231BBE\&qs=\&searchfor=video+no+Yotub+re sidencia+agr\%C3\%A1ria+assentamento+areias\&si=\&s $\mathrm{s}=\mathrm{sub} \& \mathrm{st}=\mathrm{sb} \& \mathrm{tpr}=\mathrm{sbt} \& \mathrm{vidOrd}=1 \& \mathrm{vidId}=\mathrm{IwQxnlma} 2 \mathrm{P}$ $\mathrm{U}$
}

1. ${ }^{11}$ Outros resultados sobre a produção agroecológica e orgânica, obtidos com o curso de Residência Agrária podem ser encontrados nos seguintes endereços:http://int.search.tb.ask.com/search/video. jhtml?n=783a37e8\&p2=\%5ECPC\%5Echr999\%5ES $20164 \% 5 \mathrm{E} \& \mathrm{pg}=\mathrm{video} \& \mathrm{pn}=1 \& \mathrm{ptb}=86555 \mathrm{FA} 2-$ 93A0-425D-971A-

54D2EF231BBE\&qs=\&searchfor=Resid\%C3\%AA ncia+Agr\%C3\%A1 ria+UFGD\&si=\&ss $=$ sub \&st $=$ sb $\&$ tpr $=$ hst\&ots $=1504986869358$

2. http://int.search.tb.ask.com/search/video.jhtml?n=7 83a37e8\&p2=\%5ECPC\%5Echr999\%5ES20164\%5 $\mathrm{E} \& p g=$ video $\& \mathrm{pn}=1 \& \mathrm{ptb}=86555 \mathrm{FA} 2-93 \mathrm{~A} 0-425 \mathrm{D}-$ 971A-

54D2EF231BBE\&qs=\&searchfor=Resid $\%$ C3\%AA ncia+Agr\%C3\%A1ria+UFGD\&si=\&ss=sub\&st=sb $\&$ tpr $=$ hst\&ots $=1504986869358$

3. http://int.search.tb.ask.com/search/video.jhtml? $\mathrm{n}=7$ 83a37e8\&p2=\%5ECPC\%5Echr999\%5ES20164\%5 $\mathrm{E} \& \mathrm{pg}=$ video\&pn=1\&ptb=86555FA2-93A0-425D971A-

54D2EF231BBE\&qs=\&searchfor $=$ Resid $\%$ C3\%AA $\mathrm{ncia}+\mathrm{Agr} \% \mathrm{C} 3 \% \mathrm{~A} 1 \mathrm{ria}+\mathrm{UFGD} \& \mathrm{si}=\& \mathrm{ss}=\mathrm{sub} \& \mathrm{st}=\mathrm{sb}$ $\&$ tpr=hst\&ots $=1504986869358$

4. http://int.search.tb.ask.com/search/video.jhtml?n=7 83a37e8\&p2=\%5ECPC\%5Echr999\%5ES20164\%5 
Verificou-se que ocorreu um impacto científico pelo aprendizado de novas técnicas e aplicabilidade na criação dos animais. Houve resultados efetivos e eficientes pelo conhecimento adquirido, implicando no processo de criação adequada, ou seja, os objetivos estabelecidos foram atingidos. $\mathrm{O}$ aumento do conhecimento culminou com o aumento da habilidade relacionado com a atividade resultando em retorno financeiro ao grupo que os motivaram ainda mais em expandir a produção de mel. Os resultados foram fundamentais para aumentar a expectativa das famílias envolvidas.

O conhecimento tecnológico da técnica de seleção de rainhas surtiu efeito positivo. $\mathrm{O}$ sucesso da atividade da apicultura está diretamente ligado ao aprimoramento das técnicas de exploração utilizadas. Várias são

$\mathrm{E} \& p g=$ video $\& \mathrm{pn}=1 \& \mathrm{ptb}=86555 \mathrm{FA} 2-93 \mathrm{~A} 0-425 \mathrm{D}-$ 971A-

54D2EF231BBE\&qs=\&searchfor=Resid\%C3\%AA ncia+Agr\%C $3 \%$ A1 ria+UFGD\&si=\&ss $=$ sub\&st=sb $\&$ tpr $=$ hst\&ots $=1504986869358$

5. http://int.search.tb.ask.com/search/video.jhtml?n=7 83a37e8\&p2=\%5ECPC\%5Echr999\%5ES20164\%5 $\mathrm{E} \& \mathrm{pg}=$ video\&pn $=1 \& \mathrm{ptb}=86555 \mathrm{FA} 2-93 \mathrm{~A} 0-425 \mathrm{D}-$ 971A-

54D2EF231BBE\&qs=\&searchfor=Resid\%C3\%AA ncia+Agr\%C3\%A1ria+UFGD\&si=\&ss=sub\&st=sb \&tpr=hst\&ots $=1504986869358$

6. http://int.search.tb.ask.com/search/video.jhtml?n=7 83a37e8\&p2=\%5ECPC\%5Echr999\%5ES20164\%5 $\mathrm{E} \& \mathrm{pg}=$ video $\& \mathrm{pn}=1 \& \mathrm{ptb}=86555 \mathrm{FA} 2-93 \mathrm{~A} 0-425 \mathrm{D}-$ 971A-

54D2EF231BBE\&qs=\&searchfor $=$ Resid $\%$ C3\%AA ncia+Agr\%C3\%A1ria+UFGD\&si=\&ss=sub\&st=sb $\&$ tpr=hst\&ots $=1504986869358$ as técnicas desenvolvidas para alcançar esse aprimoramento, podendo-se destacar apicultura migratória, o controle de enxameações, a seleção de colmeias produtivas e a criação de rainhas que atendam o interesse do produtor. A criação de rainhas é uma pratica que vem sendo realizadas pelos produtores desde o final do século XVIII (LAIDLAW Jr., 1998). A rainha é a personagem central e mais importante da colmeia, dela que depende a harmonia dos trabalhos da colônia, bem como a reprodução da espécie, sendo responsável pelo equilíbrio da colmeia. As rainhas melhoradas de boa procedência apresentam maior capacidade de postura, resultando, assim, em colmeias mais fortes e produtivas de menor índice de nascimento de zangões e redução do instinto de enxameação das abelhas (WIESE, 2005).

Importante foram os resultados referentes ao impacto econômico, culminando com o aumento produção de mel. Com os materiais adquiridos, conforme relatam Grassieli et al. (2017), o grupo passou a desenvolver a atividade, sendo que na primeira safra, retirada no mês de dezembro, coletaram $434 \mathrm{~kg}$ de mel, e ainda deixaram sobra de $54 \mathrm{~kg}$ para alimentar os enxames, resultado que promoveu contentamento no grupo e despertou interesse por parte de outras pessoas do assentamento, de 
integrarem o grupo na produção de mel. $\mathrm{O}$ crescimento da atividade se deve muito a toda preparação concedida aos assentados com assistência técnica de qualidade e cursos básicos oferecidos através de uma parceria firmada pela UFGD e empresa Apiário Carbonari. Além disso, o acesso as pesquisas científicas aplicadas à apicultura brasileira, nas últimas décadas, que têm sido numerosas e de grande qualidade, possibilitando referenciais técnicos para melhoria no manejo, o que resultou no aumento da produtividade das colmeias. Estes, quando publicados, circulam e acabam por servir aos produtores para o aprimoramento da atividade apícula.

No entanto, existe uma lacuna quanto os resultados de pesquisas, no que se refere aos aspectos econômicos, pois grande parte dos apicultores necessita de suporte e orientação, em relação à estruturação, gestão, monitoramento e avaliação da atividade e comercialização de produtos apícolas. Visando analisar a apicultura como um mecanismo para promoção da inclusão social em assentamentos de reforma agrária, Martins et al. (2006), detectaram que a atividade da apicultura tem contribuído, decisivamente, para gerar ocupação e renda para agricultores familiares, melhorando sensivelmente $\mathrm{o}$ padrão e a qualidade de vida dos mesmos.
Outro resultado já apontado anteriormente, mas que é preciso enfatizá-lo, obtido com a apicultura no Areias, foi o impacto social, visto que é um trabalho que vem promovendo maior união entre as pessoas da comunidade, aliado a relação com os discentes e docentes da UFGD. Nesse sentido corrobora-se com Andrade et al. (2013), quando aponta que a organização de grupos sociais é uma ação que motiva alcançar o interesse comum de todos, sendo de extrema importância oferecer suporte organizacional para famílias que se encontram em fase inicial do processo de implantação dos assentamentos. É necessário oferecer condições para o desenvolvimento dos diferentes grupos de interesses préidentificados, bem como apoiar, caso seja da vontade das famílias, a formalização de associações e cooperativas (ANDRADE et al., 2013).

É preciso destacar que as casas do assentamento Areias, são simples em sua estrutura, se considerada em termos de sua edificação, mas isso não significa que lá exista carência de alimentos e/ou fome. O alimento diário parece ser o principal aspecto nutrido pelas pessoas assentadas, aspecto observado durante a execução da ação, quando a equipe de professores e alunos era constantemente recebida nas diversas 
residências do Areias, com o oferecimento de algum tipo de alimento. Isso mostra que falar da produção em área de assentamento, requer atentar para o que indica Alzira Salete Menegat (2015, prefacio do livro ALMEIDA, 2015), quando aponta que o chão do assentamento é constituído de múltiplos elementos que se entrelaçam, e fazem com que a vida cotidiana se organize com base na produção, mas também nos cheiros, nos sabores, nos projetos e nos referenciais da memória a guiá-los. Esses referenciais atuam como um elo que faz a ponte entre o que eram antes de assentados e o que hoje são produtores de alimentos, e ainda o que poderão vir a ser.

Uns dos aspectos que se manifestou com ênfase nas discussões do grupo foram em relação aos cuidados que devem manter com a questão do impacto ambiental, especialmente atendo-se ao fato de que a área do assentamento está localizada na entrada do Pantanal, lugar considerado de proteção ambiental. O que certamente os resultados estão sendo favoráveis pelo fato do grupo envolvido com a ação ter a preocupação em manter a preservação de espécies nativas e promover o aumento da polinização de plantas produtoras de néctar. Ademais, a apicultura é uma atividade econômica de baixo impacto ambiental e que possibilita a utilização dos recursos naturais, de maneira que contribui com a manutenção e a preservação dos ecossistemas já existentes.

A intenção dos docentes da UFGD foi ampliar os resultados anteriormente alcançados com a atividade produtiva, firmando caminhos para que os assentados compartilhassem e acumulassem orientações técnicas do manejo com a apicultura, alcançando autonomia na produção do mel. Nesse formato consiste a lógica da extensão universitária, que tem como objetivo primordial potencializar as experiências dos grupos, e associar a elas os saberes acadêmicos, ampliando as possibilidades produtivas que podem resultar em melhoria na qualidade de vida de grupos sociais.

A combinação entre saberes cotidianos e saberes científicos, amplia a dimensão dos resultados porque possibilita ultrapassar o âmbito da produção agrícola, visto que a reunião de pessoas em grupos de produção acaba por criar sociabilidades entre seus integrantes, que extrapolam as metas iniciais, quando apenas se almejava melhoria na produção e na geração de renda. Eis o resultado objetivado com a extensão universitária, e que por vezes é difícil de ser estatisticamente computado, especialmente pelo fato de contar com a soma de indicadores de contentamento, de sociabilidade, de 
melhoria nas relações sociais coletivas, elementos alcançados e bem presentes no grupo do Areias.

Com a lógica do grupo é possível fomentar o sentido da parceria entre a vizinhança, necessária no modelo de assentamento rural, visto que as famílias assentadas se encontram localizadas distantes de núcleos urbanos, e com o incremento do sentimento de grupo, podem contar, em momentos de necessidades, com a ajuda dos vizinhos. Criam, ainda, vínculos que viabilizam outros encontros, como se pode constatar naquela comunidade, nos encaminhamentos com o laser, nos momentos de descanso, com a organização de ações de sociabilidade, configuradas nas festas comemorativas quando reúnem esforços em torno dos almoços coletivos, bailes, jogos de futebol, dentre outros momentos, que fortalecem os laços entre os membros do grupo.

Nesse formato organizativo, o trabalho com o apiário, aliado ao desejo de ampliarem a cadeia de produção visando melhoria alimentar e geração de renda com a venda do excedente da produção acaba por se constituir em um elo que fortalece fundamentalmente o sentimento de pertencimento com o assentamento, fixando pessoas na produção agrícola e levando-as a se reconhecerem no lugar e na atividade que desempenham, se valorizando a elas próprias na pequena produção de alimentos saudáveis.

\section{Conclusão}

A atividade da apicultura foi desejada e bem aceita pelos pequenos produtores do assentamento Areias que para sua organização dialogaram com professores da UFGD e assessores técnicos, construindo etapas que favorecessem não apenas a obtenção de resultados produtivos com a produção de mel, mas especialmente que a apicultura se configurasse num trabalho de integração comunitária, reunindo a vizinhança.

Para que a mesma ocorresse, pessoas do assentamento que se identificavam com a apicultura, se juntaram e formaram um grupo de trabalho, por meio do qual participaram de reuniões técnicas e organizativas planejando as diversas etapas que envolvem a implementação de apiário. Nelas, ocorreu comprometimento de todos os envolvidos na execução desta prática que resultou em retorno financeiro para o grupo e despertou o interesse de outras famílias em fazerem parte da equipe.

Resultou, ainda, numa maior integração entre famílias assentadas, que extrapolou a dimensão produtiva e firmaram 
sociabilidades, necessárias para pessoas que vivem as agruras do meio rural, constituído de um viver tranquilo, se comparado ao viver urbano, mas carecendo de assistência em diversas instancia da vida, especialmente de auxílio nos momentos de enfermidades. Nesse sentido o fortalecimento de laços entre a vizinhança se apresenta como fundamental para os eventos difíceis. Cria, ainda, possibilidades de compartilhar conhecimentos, visto que cada pessoa tem uma experiência, construída ao longo de sua trajetória, parte dela vivida em espaços da agricultura. Quando colocada no grupo, e reunida com saberes acadêmicos, promove ressignificação e amplia resultados em diversas direções: produtivos, políticos, sociais, de lazer, enfim, de fraternidade.

\section{Referências Bibliográficas}

ANDRADE, A.A.X.; MOREIRA, D.C.; MOURA, R.A. O papel da organização social e ambiental nos assentamentos rurais. Espaço do Produtor, 07 fev. 2013.

BOTH, J.P.C.L.; BOTH, A.L.C.M.; KATO, O.R.; OLIVEIRA, T.F. Mel na Composição da Renda em Unidades de Produção Familiar no Município de Capitão Poço, Pará, Brasil. In: CONGRESSO LATINO AMERICANO DE AGROECOLOGIA E CONGRESSO BRASILEIRO DE AGROECOLOGIA, 2 e 6, 2009, Curitiba. Anais...Curitiba:Congresso Latino Americano de Agroecologia e Congresso Brasileiro de Agroecologia. Curitiba, 2009.

CARVALHO, P.A.S.; TORRES, K.A.; BORBA, E.L.; Analise da gestão de pessoas na administração pública: um estudo de caso. In: SIMPÓSIO DE EXCELÊNCIA EM GESTÃO E TECNOLOGIA - SEGeT, XII, 2015,Rezende. Anais...Rezende: Simpósio de Excelência em Gestão e Tecnologia - SEGeT, Rezende, 2015.

ESMERALDO, G.G.I. S. L.; FABRE, N. A.;FERNANDES, I. L. C.;MOREIRA, M. L. S. M. O PRONERA na reforma agrária e a pesquisa em agroecologia. In: MOLINA, M. C.; SANTOS, C. A.; MICHELOTTI, F.; SOUSA, R. P.(Orgs.). Práticas contra-hegemônicas na formação dos profissionais das Ciências Agrárias. Brasília: Ministério do Desenvolvimento Agrário, 2014. 292 p.

GRASSIELI, A.A. et al. Organização do trabalho na produção de mel: um estudo de caso no assentamento Areias. In: MENEGAT, A.S.; FAISTING, A.L.; OLIVEIRA, E.R.; PEREIRA, Z.V. (Orgs.) Extensão rural, agroecologia e produção animal e vegetal em lotes de assentamentos rurais e sítios de colonização em Mato Grosso do Sul. Dourados-MS: Seriema, 2017. p. 17-43.

LAGO, A.; LENGLER, L.; CORONEL, D.A.;SILVA,T.N.Agricultura familiar de produtos orgânicos: Um olhar sob a ótica do marketing. Revista Extensão Rural, Santa Maria,n.13, p. 93116, Jan./Dez. 2006. 
LAIDLAW Jr., H.H. Criação Contemporânea de Rainhas. Tradução de Carlos Alberto Osowski. São Paulo: Ed. do Autor, 1998. 210 p.

LOPES, C.G.R.; BEIRÃO, D.C.C.; PEREIRA, L.A.; ALENCAR, L.C. Levantamento da flora apícola em área de cerrado no município de Floriano, estado do Piauí, Brasil. Revista Brasileira de Biociências. Porto Alegre, v.14, n.2, p. 102-110, abril./jun. 2016.

MARTINS, J.C.V.;OLIVEIRA, A.M.; MARACAJÁ, P.B. Apicultura e inclusão social em assentamentos de reformaagrária no município de APODI-RN. In: CONGRESSO DA SOBER "Questões Agrárias, Educação no Campo e Desenvolvimento", XLIV., 2006,Fortaleza. Anais...Fortaleza:Sociedade Brasileira de Economia e Sociologia Rural, 2006.p.1-19.

MENEGAT, A. S.. Prefácio da Obra In: AlMEIDA, R. A. (org.) A práxis Agroambiental no chão do assentamento. Campo Grande: UFMS, 2015.p. 9-14.

NUNES, F. P.; SOUZA, M. C.; ROZA, N. G. N. Trajetórias de migrantes: o fim do anonimato. In: OLIVEIRA, B. C. (Org.). Histórias que (re)contam história: análise do povoamento, colonização e reforma agrária do sul de Mato Grosso do Sul. Dourados: Ed. UFGD, 2013. 142 p.

REIS, V.D.A. Mel Orgânico: Oportunidades e Desafios para a Apicultura no Pantanal. Corumbá: EMBRAPA, 2003. 26p. (Documentos, 59).

SANTOS, A.C.G. Ação e mediação da informação em cooperação institucional. In: ENCONTRO NACIONAL DE PESQUISA EM CIÊNCIA DA INFORMAÇÃO, 16, 2015, João Pessoa. Anais...João Pessoa:UFRA, 2015.

SÁ, L. M.;MOLINA, M. C.. Educação superior do campo: contribuições para a formação crítica dos profissionais das Ciências Agrárias. In: MOLINA,M.C.; SANTOS, C.A.; MICHELOTTI, F.; SOUSA, R.P.(Orgs.). Práticas contra-hegemônicas na formação dos profissionais das Ciências Agrárias. Brasília: Ministério do Desenvolvimento Agrário, 2014. 292 p.

SOARES, A.E.E. Manejo de caixas iscas e suas implicações com a prevenção de acidentes. In: CONGRESSO BRASILEIRO DE APICULTURA, 12, Salvador, 1998. Anais...Salvador: Confederação Brasileira de Apicultura, 1998. p.61-65.

SOUZA, D.T.M.; COUTO, R.H.N.; COUTO, L.A.; SOUZA, J.C. Atrativo para as abelhas Apismellifera e polinização em café (Coffeaarábica, L.). Brazilian Journal of Veterinary Research and Animal Science, USP:São Paulo, n.40, v.3, p.272-278, 2003.

WIESE, H. Apicultura: Novos Tempos. 2. ed. Guaíba: Agrolivros, 2005. 378 p 